\title{
Contact Force Distribution Analysis on a Single-row Four Point Contact Ball Slewing Bearing
}

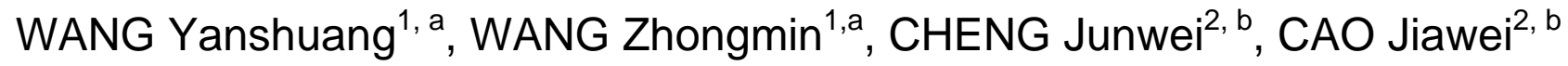 \\ ${ }^{1}$ College of Mechanical Engineering, Tianjin University of Technology and Education, Tianjin 300222, \\ China \\ ${ }^{2}$ Henan University of Science and Technology, Luoyang 471003, China \\ ahkd_wang_yan_shuang@126.com \\ bChengjw55a@163.com
}

Keywords: contact force distribution, four-point-contact, load capacity, slewing bearing

\begin{abstract}
Contact force distribution analysis is the foundation of the load-carrying capacity analysis, the drawing of static load-carrying capacity curve, designing and selecting of slewing bearings. The static model of the single-row four point contact ball slewing bearing is established and the contact force distributions are solved under different types of load. The characteristics of contact force distribution of this bearing are analyzed and the influence of bearing parameters on contact force distribution is analyzed. Results show that the characteristics of contact force distributions on raceway are different under different types of load. With the increase in the contact angle and the decrease in the groove curvature radius coefficient, the loads on raceway decrease and the load-carrying capacity of bearing increases.
\end{abstract}

\section{Introduction}

The single-row four point contact ball slewing bearing can bear axial load, radial load and overturning torque simultaneously. It can be widely used in hoisting, mining, wind power, medical and other slewing machineries. In most cases, the movement of this kind of bearing is so low that the static analysis is enough.The load distribution of the slewing bearing determines the maximum load applied on the most heavily loaded rolling element, the maximum contact stress distribution on the raceway and the bearing stiffness. It is significant to research the load distribution of the slewing bearing. In literature [1], the effect of the inner and outer raceways' size on the load distribution and the structural stiffness of single-row four-point-contact ball slewing bearings were analyzed. The static equilibrium equations for single-row four-contact-point ball slewing bearing were established and the computed results under pure axial, radial and overturning moment loads were given in literature [2]. In literature [3], a quasi static analytical model of four-contact-point ball slewing bearing with five degrees of freedom was established under no applying load considering the centrifugal force, gyroscopic moment and friction. The influence of the clearance on the load distribution of a single-row four-contact-point ball slewing was discussed in literatures [4-6]. A model to calculate the static load-carrying capacity and fatigue life of the large slewing bearing was presented in literature [7].

According to the static theory and the internal geometry deformation of the bearing [8], the calculation model considering the bearing clearance is established in this paper. The numerical algorithm is used to solve the load distribution. The characteristics of load distribution under different load conditions and the influence of the geometry parameters on the load distribution are analyzed. The research results in this paper can provide a theoretical basis for the drawing of the bearing load-carrying capacity curve and the improvement of the bearing load-carrying capacity. 


\section{Static model}

In order to simplify the analysis and calculation, the following hypotheses were adopted: 1) the inner and outer rings of bearing are rigid, the deformation occurs on the ball-raceway contact; 2) the radial load and bending moment act on the same plane; 3)under external load, outer ring is fixed in the space and the inner ring produces a corresponding displacement.

Four-contact-point ball slewing bearings have four raceways. There are two contact pairs between the ball and the four raceways. Before loading, the distance between the curvature centers of the inner and outer raceways is:

$$
A=\left(f_{\mathrm{i}}+f_{\mathrm{e}}-1\right) D_{\mathrm{w}}-0.5 G_{\mathrm{a}} \cos \alpha_{0}
$$

where $f_{i}$ is the coefficient of inner raceway groove curvature radius, fe is the coefficient of outer raceway groove curvature radius, $D_{w}$ is the nominal diameter of ball, $G_{a}$ is the axial clearance of bearing, and $\alpha_{0}$ is the initial contact angle.

The radius of the track of raceway groove curvature center of the inner ring is:

$$
R_{\mathrm{i}}=0.5 D_{\mathrm{pw}}+\left(f_{\mathrm{i}}-0.5\right) D_{\mathrm{w}} \cos \alpha_{0}-\frac{1}{4} G_{\mathrm{a}} \cos ^{2} \alpha_{0}
$$

where $\mathrm{D}_{\mathrm{pw}}$ is the pitch diameter of bearing.

At any angular position, the distance between the curvature centers of the inner and outer raceways when there is no contact deformation between the rolling element and raceway can be written as:

$$
A_{0}=\left(f_{\mathrm{i}}+f_{\mathrm{e}}-1\right) D_{\mathrm{w}}
$$

After combination loads of the axial force $F_{a}$, radial force $F_{r}$ and overturning moment $M$ are applied on the bearing, the radial displacement $\delta_{r}$, axial displacement $\delta_{a}$ and angular displacement $\theta$ of the inner ring are caused. At the same time, the distance between the curvature centers of the inner and outer raceways is also changed, as shown in Figure 1. The changed distances between the curvature centers of the contact pair 1 and the contact pair 2 are:

$$
\begin{aligned}
& S_{1 \phi}=\left[\left(A \sin \alpha_{0}+\delta_{a}+R_{i} \theta \cos \phi\right)^{2}+\left(A \cos \alpha_{0}+\delta_{\mathrm{r}} \cos \phi\right)^{2}\right]^{1 / 2} \\
& S_{2 \phi}=\left[\left(A \sin \alpha_{0}-\delta_{\mathrm{a}}-R_{\mathrm{i}} \theta \cos \phi\right)^{2}+\left(A \cos \alpha_{0}+\delta_{\mathrm{r}} \cos \phi\right)^{2}\right]^{1 / 2}
\end{aligned}
$$

where $\phi$ is the angular position of each ball inside the bearing.

The contact angles of the two contact pairs are changed to:

$$
\begin{aligned}
& \sin \alpha_{1 \phi}=\left(A \sin \alpha_{0}+\delta_{a}+R_{i} \theta \cos \phi\right) / S_{1 \phi} \\
& \cos \alpha_{1 \phi}=\left(A \cos \alpha_{0}+\delta_{r} \cos \phi\right) / S_{1 \phi} \\
& \sin \alpha_{2 \phi}=\left(A \sin \alpha_{0}-\delta_{a}-R_{i} \theta \cos \phi\right) / S_{2 \phi} \\
& \cos \alpha_{2 \phi}=\left(A \cos \alpha_{0}+\delta_{r} \cos \phi\right) / S_{2 \phi}
\end{aligned}
$$

Contact deformation in angular position $\phi$ along the direction of the two contact pairs, due to normal contact force acting on balls and raceways can be calculated by:

$$
\delta_{\mathrm{j \phi}}=S_{\mathrm{j \phi}}-A_{0},(\mathrm{j}=1,2)
$$

The contact force on the two contact paris can be expressed by:

$$
Q_{\mathrm{j} \phi}=\left\{\begin{array}{l}
K_{\mathrm{n}} \delta_{\mathrm{j} \phi}^{1.5}, \forall \delta_{\mathrm{j} \phi} \geq 0 \\
0, \forall \delta_{\mathrm{j} \phi}<0
\end{array} \quad(\mathrm{j}=1,2)\right.
$$

where $K_{n}$ is the load deformation constant.

The inner ring is in a state of equilibrium under the external loads and the contact forces, the equilibrium equations are:

$$
\begin{aligned}
& F_{\mathrm{a}}=\sum_{\phi=0}^{\phi=2 \pi} Q_{1 \phi} \sin \alpha_{1 \phi}-\sum_{\phi=0}^{\phi=2 \pi} Q_{2 \phi} \sin \alpha_{2 \phi} \\
& F_{\mathrm{r}}=\sum_{\phi=0}^{\phi=2 \pi} Q_{1 \phi} \cos \alpha_{1 \phi} \cos \phi+\sum_{\phi=0}^{\phi=2 \pi} Q_{2 \phi} \cos \alpha_{2 \phi} \cos \phi
\end{aligned}
$$




$$
M=0.5 D_{\mathrm{pw}}\left(\sum_{\phi=0}^{\phi=2 \pi} Q_{1 \phi} \sin \alpha_{1 \phi} \cos \phi-\sum_{\phi=0}^{\phi=2 \pi} Q_{2 \phi} \sin \alpha_{2 \phi} \cos \phi\right)
$$

The above equations (12) $\sim(14)$ are the three nonlinear equations taking the inner displacements $\delta_{r}, \delta_{a}$ and $\theta$ as unknown variables. The load distribution can be obtained by numerically solving the above equations if the external loads are given.

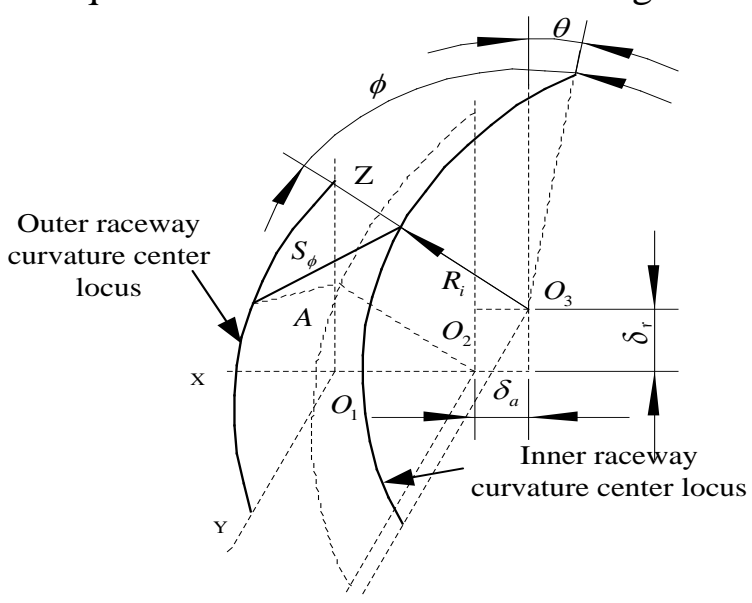

Fig. 1 Relative displacement between inner and outer rings

\section{Load distribution under different loads}

\section{Load distribution under the radial force}

Taking a certain type of slewing bearing as an example, the bearing parameters are as shown in Table 1 . When the clearance is $0.05 \mathrm{~mm}$, the load distributions on the balls under the different radial forces are shown in Figure 2. As can be seen from the figure, when the bearing only bear pure radial load, contact pari1 and contact pari2 which have the same position angle bear the same contact loads. This is mainly because the displacement of the inner ring of the bearing only occurred in the radial direction after the load is applied, the deformation of the two contact pairs of each ball and raceway

Table 1 Slewing bearing parameters

\begin{tabular}{cc}
\hline Parameters & Value \\
\hline The ball diameter [mm] & 50.8 \\
The number of balls & 70 \\
Bearing pitch circle diameter [mm] & 1300 \\
Inner raceway groove curvature radius & 0.525 \\
$\quad$ coefficient & 0.525 \\
The outer raceway groove curvature & \\
$\quad$ radius coefficient & 45 \\
The original contact angle $\left[{ }^{\circ}\right]$ &
\end{tabular}

are equal. With the increase in the radial force, the maximum contact load increases, and the number of the ball bearing load increases. This is mainly because the bearing clearance is positive. When the bearing bear small radial force, the displacement of inner ring along the radial is small. Due to the bearing clearance, the contact deformation between the steel ball and the raceway is small, which leads to the decrease in the contact load. With the increase in the radial force, the displacement of inner ring increases, the number of the ball bearing load increases, the contact load increases.

\section{Load distribution under the overturning moment}

Taking the bearing whose parameters are listed in Table 1 as an example, the load distribution on the balls are as shown in Figure 3 when the overturning moment is $35000 \mathrm{~N}$. m. We can see from Figure 3, when the bearing only bears overturning moment, the distribution of contact loads on balls is symmetry. The maximum contact loads are applied on the balls whose position angles are $0^{\circ}$ and 
$180^{\circ}$. This is mainly because the inner ring only occurs relative angular displacement after the overturning moment is applied.
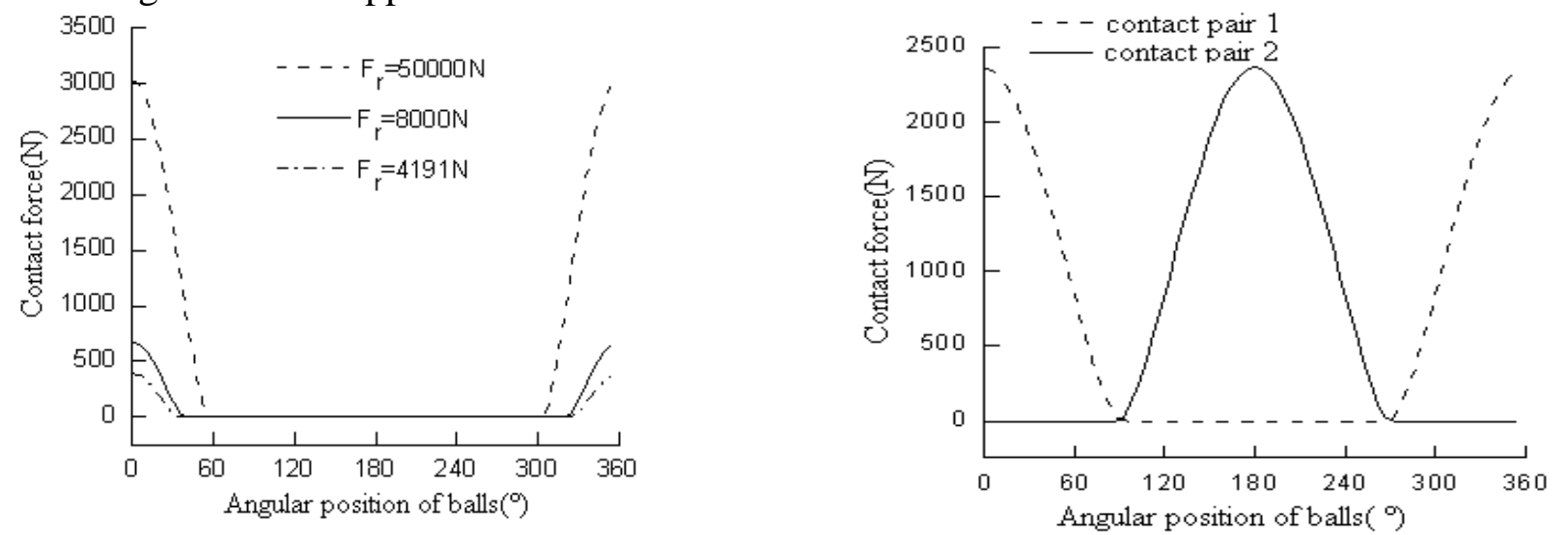

Fig. 2 Contact force distributions on balls under Fig. 3 Contact force distributions on balls under the radial forces

\section{Load distribution under the combined loads}

overturning moment

Taking the bearing whose parameters are listed in Table 1as an example, the load distributions on balls are as shown in Figure 4 when the axial, radial and overturning moment loads are 48kN, $4191 \mathrm{~N}$ and $35 \mathrm{kN} \cdot \mathrm{m}$ respectively. It can be seen from the Figure that when the bearing is subjected to the combined loadings, all the balls come into contact with the raceway along the contact pair 1 , some balls come into contact with the raceway along the contact pair 2 . The maximum contact force along contact pair 1 is greater than that along contact pair 2 . The external load type and load amplitude of the bearing affect the distribution of contact force.

\section{Influence of bearing parameters on the contact force distribution.}

\section{Effect of clearance on the bearing contact force distribution}

Taking the bearing whose parameters are listed in Table 1 as an example, the contact force distributions on the balls are shown in Figure 5 for different clearances when the axial, radial and overturning moment loads are $48 \mathrm{kN}, 4191 \mathrm{~N}$ and $35 \mathrm{kN} \cdot \mathrm{m}$ respectively.

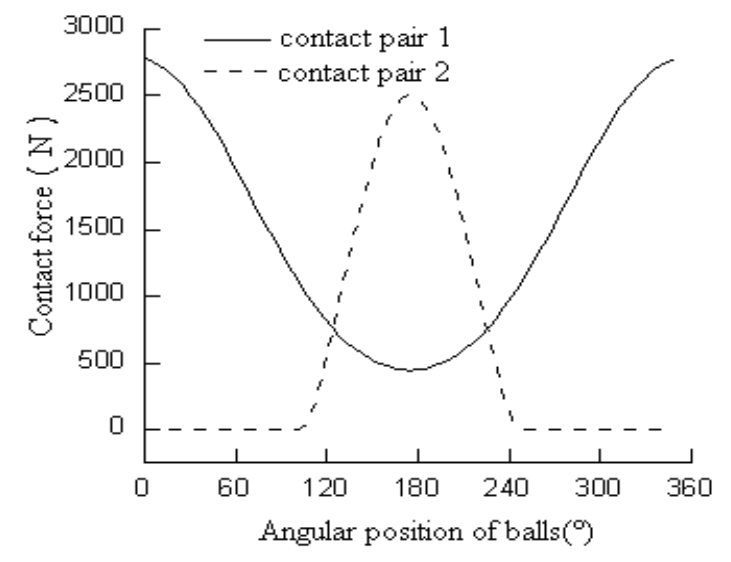

Fig. 4 Contact force distributions on balls under combined loads

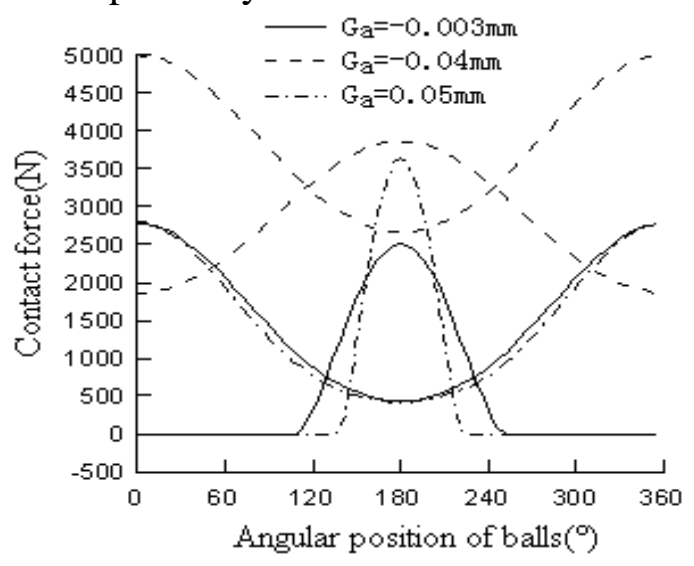

Fig. 5 Contact force distributions for different clearances

We can see from Figure 5 that when the positive clearance is adopted , the maximum contact force on the ball increases. When the absolute value of the negative clearance is small, the contact forces on several balls close to the maximum contact force increase. When the position angles of balls range from $16^{\circ}$ to $340^{\circ}$, the contact forces along the contact pair 1 increase. When the position angles range from $110^{\circ}$ to $150^{\circ}$ and $201^{\circ}$ to $250^{\circ}$, the contact forces along contact pair 2 increase, contact forces at the other balls decrease. But when the absolute value of negative axial play is big, contact forces on all balls increase. For example, contact forces on all balls increase when the clearance is -0.04 . This is mainly because the number of balls bearing load is small when the bearing clearance is positive, the 
number of balls bearing load is big when the bearing clearance is negative. The maximum contact force under negative clearance is smaller than that under positive clearance. Before the external loads are applied, the negative clearance between the ball and the raceway has aroused predeformation, so the contact forces on some balls are greater than that under positive clearance. when the absolute value of negative clearance increases, the pre-deformation increases, the maximum contact force of bearing increases, the number of ball bearing loads increases. So the bearing clearance has great influence on the bearing contact force distribution and contact stress on raceways.

\section{Effect of contact angle on bearing contact force distribution}

Taking the bearing whose parameters are listed in Table 1 as an example, the contact force distributions on the balls are shown in Figure 6 for different contact angles when the axial, radial and overturning moment loads are $48 \mathrm{kN}, 4191 \mathrm{~N}$ and $35 \mathrm{kN} \cdot \mathrm{m}$ respectively.

We can see from Figure 6, when the contact angle increases, the contact force of bearing decreases. This is mainly because the four point contact ball bearing mainly bears axial force and overturning moment. The larger the contact angle is, the smaller the contact forces on the balls caused by axial force and overturning moment are. The larger the contact angle is, the bigger the contact forces on the balls caused by the radial force are. The decreasing amplitude is bigger than the increasing amplitude. So, the contact forces between the balls and the raceways decrease. The increase in the contact angle is beneficial to improve the bearing load capacity.

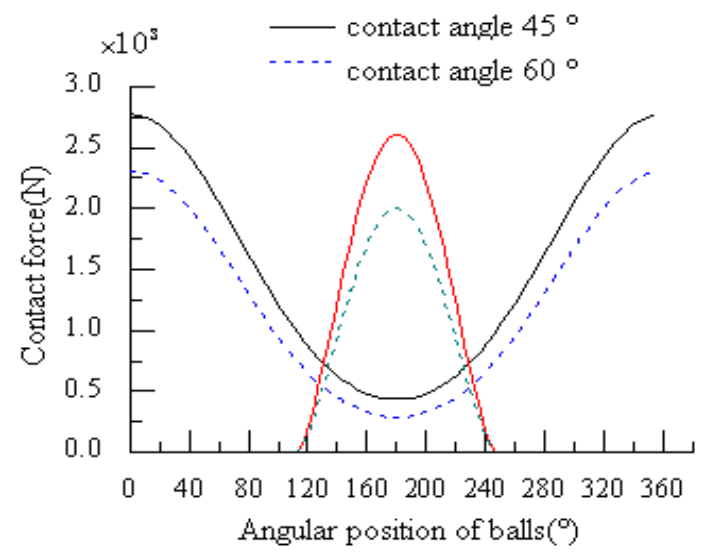

Fig. 6 Contact force distributions for different groove contact angles

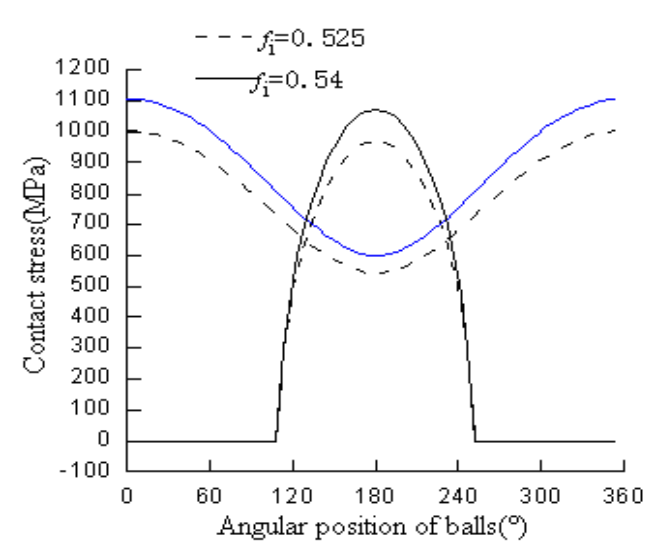

Fig. 7 Contact stress distributions for different curvature radius coefficients

\section{Effect of groove curvature radius coefficient on contact stress of bearing}

Taking the bearing whose parameters are listed in Table 1 as an example, the contact stress distributions on the balls are shown in Figure 7 for different groove curvature radius coefficients when the axial, radial and overturning moment loads are $48 \mathrm{kN}, 4191 \mathrm{~N}$ and $35 \mathrm{kN} \bullet \mathrm{m}$ respectively. The Figure shows that the bearing contact stress increases with the increase in the groove curvature radius coefficients. The decrease in the groove curvature radius coefficient is beneficial to improve the bearing load capacity.

\section{Conclusion}

The static model of a single-row four-point-contact ball slewing bearing is established and the influences of different operating conditions and bearing parameters on the contact force distribution of bearing is analyzed. The contact force distributions are different for different external loads. Bearing clearance has great influence on the bearing contact force distribution and contact stress on the raceway. Increasing the bearing contact angle and decreasing the groove curvature radius coefficient can improve the bearing load capacity. 


\section{Acknowledgements}

The paper is supported by NSFC (51475143), NSFC (51105131) and Henan province key scientific and technological project (142102210110)

\section{References}

[1] S ZUPAN,I PREBIL.Carrying angle and carrying capacity of a large single row ball bearing as a function of geometry parameters of the rolling contact and the supporting structure stiffness[J]. Mechanism and Machine Theory,2001,(2):1087- 1103.

[2] J IGNACIO AMASORRAIN,X SAGARTZAZU,J DAMIAN.Load distribution in a four contact-point slewing bearing[J] .Mechanism and Machine Theory,2003,38:479-496.

[3] A LEBLANC, D NELIAS. Ball motion and sliding friction in a four-contact-point ball bearing[J].Journal of Tribology,2007,192: 801-808.

[4] G Z CHEN,S R XU,Y Z YANG,Y S WANG, S E DENG.Contact stress analysis on large-sized four-contact-point ball bearing with negative axial play[J].Journal of Mechanical Transmission, 2009,33(5):83-85.

[5] Y F LI, Z Y Wu, B H LU, G G ZhAO,L M SUN. Influence of clearance on load distribution of single row four-point contact ball slewing bearings[J]. Journal of Mechanical Transmission, 2010,34(3): 56-58.

[6] L CHEN, L C ZHAO,X T XIA,M QIU[J]. Analysis on load distribution of pitch bearing[J]. Bearing, 2010(1):1-4.

[7] S Glodež,R Potočnik,J Flašker.Computational model for calculation of static capacity and lifetime of large slewing bearing's raceway[J].Mechanism and Machine Theory,2011(8): 1-15.

[8] TAHARRIS. Rolling bearing analysis[M].New York: John Wiley \& Sons, Inc, 1984.

[9] H WANG, Y CHEN.Calculation method for load capacity and rating life of slewing rim bearings[J].Bearing,2008(2):7-9. 